\title{
RESEARCH
}

\section{Postoperative incidence of seizure and cerebral infarction in pediatric patients with epileptic type moyamoya disease: a meta- analysis of single rate}

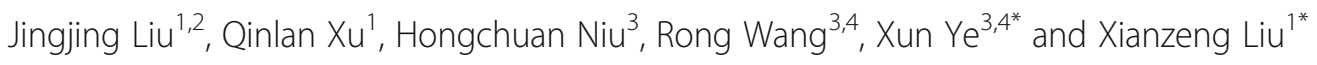

\begin{abstract}
Background: Surgery is a conventional mature treatment for moyamoya disease (MMD). However, whether surgery is also an effective therapy for epileptic type MMD has seldom been investigated systematically. The study aims to summarize the pooled postoperative incidence of seizure and cerebral infarction in pediatric patients with epileptic type moyamoya disease.

Method: The study was a systematic review and critical appraisal with a meta-analysis of cohort studies, both prospective and retrospective. Studies were identified by a computerized search of PubMed, Embase, Web of Science, Wanfang, and CNKI databases. In a literature search, a total of 7 cohort studies were identified. The $I^{2}$ statistic was used to quantify heterogeneity. A fixed-effect model was used to synthesize the results. The linear regression test of funnel plot asymmetry was used to estimate the potential publication bias.

Results: The pooled estimated postoperative incidence of seizure in pediatric patients with epileptic type moyamoya disease was $23.44 \%$. The pooled estimated postoperative incidence of cerebral infarction in pediatric patients with epileptic type moyamoya disease was $9.12 \%$. Low substantial heterogeneity and potential publication bias were present.

Conclusions: Evidence from this study suggests that the postoperative incidence of seizure and cerebral infarction is relatively low. Surgery is an effective and secure therapy for pediatric patients with epileptic type moyamoya disease.
\end{abstract}

Keywords: Moyamoya disease, Epileptic type, Seizure, Ischemic event, Surgery

\footnotetext{
*Correspondence: Yexun@pkuih.edu.cn; liuxianzeng2004@sina.com

Jingjing Liu is the first and responsible author.

Xianzeng Liu and Xun Ye are the equal corresponding authors.

${ }^{3}$ Peking University International Hospital, Department of Neurosurgery,

Peking University, Beijing, China

'Peking University International Hospital, Department of Neurology, Peking

University, Beijing, China

Full list of author information is available at the end of the article
}

(c) The Author(s). 2021 Open Access This article is licensed under a Creative Commons Attribution 4.0 International License, which permits use, sharing, adaptation, distribution and reproduction in any medium or format, as long as you give appropriate credit to the original author(s) and the source, provide a link to the Creative Commons licence, and indicate if changes were made. The images or other third party material in this article are included in the article's Creative Commons licence, unless indicated otherwise in a credit line to the material. If material is not included in the article's Creative Commons licence and your intended use is not permitted by statutory regulation or exceeds the permitted use, you will need to obtain permission directly from the copyright holder. To view a copy of this licence, visit http://creativecommons.org/licenses/by/4.0/ The Creative Commons Public Domain Dedication waiver (http://creativecommons.org/publicdomain/zero/1.0/) applies to the data made available in this article, unless otherwise stated in a credit line to the data. 


\section{Background}

Moyamoya disease (MMD) is a type of progressive occlusive cerebrovascular disease, with the significant characteristic of steno or blocked blood vessels at the end of the internal carotid artery (ICA), proximal middle cerebral artery (MCA), and anterior cerebral artery (ACA) [1]. The name "moyamoya" means "puff of smoke" in Japanese and describes the appearance of the formation of smoke-like abnormal blood vessels in the base of the skull in cerebral angiography. It frequently occurs in the East Asian population, may cause ischemic or hemorrhage stroke, epilepsy, headache, or transient ischemic attack (TIA) [2]. The epileptic seizure is the second common symptom of MMD in pediatric patients [3], and the third most common manifestation of MMD in all patients [4].MMD whose main clinical symptoms are convulsive seizures is called "epileptic type moyamoya disease" [5]. The treatment methods and clinical outcomes for this type of MMD are seldom reported.
Some of the epileptic type patients suffer seizures as the first symptom, and others may be secondary to ischemic stroke [6]. The clinical manifestation and progression of this type may be non-specific [5]. Some scholars believe that epileptic seizure in epileptic type patients is not a specific symptom but mostly caused by cerebral ischemia [7]. The cause of epilepsy in MMD could be various, including ischemic or hemorrhagic stroke [5], hyperperfusion [8], and so on. About 20-30\% of MMD patients present with seizures [9], but only 3$4 \%$ epileptic type MMD without vascular events $[10,11]$.

Revascularization operation is effective for MMD presenting with the cerebral ischemic event has been proved by multiple studies [11-14]. Surgery could reduce the frequency of TIAs and cerebral infarction, and improve the long-term prognosis of brain functions. The cerebral hemodynamics and metabolism are also improved following surgery treatment, which could be evaluated by SPECT or PET [13]. Both direct and indirect

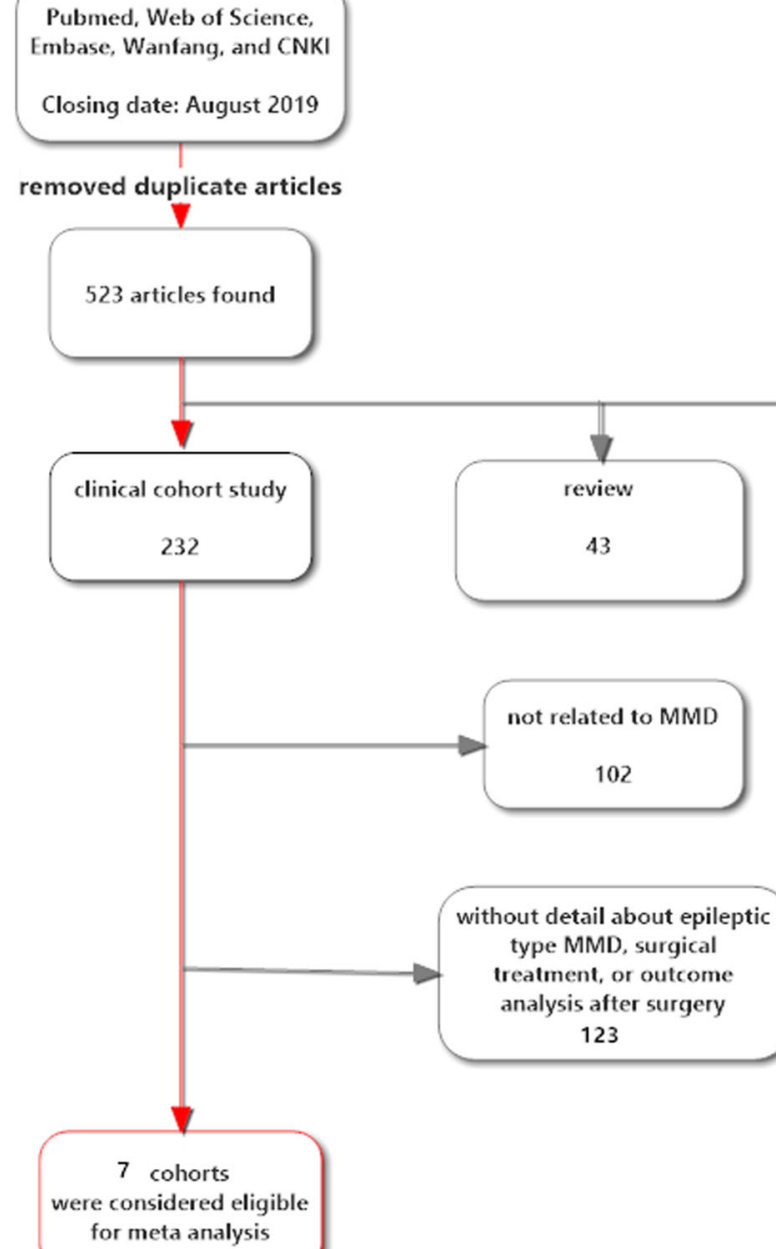

Fig. 1 Flow chart of the literature searches for the systematic review 
revascularizations or the combination of these two types could obtain satisfactory results. Since epileptic type, MMD has rarely been discussed in detail before, whether surgery could improve these patients still lack research systematically. In this study, we will summarize the pooled postoperative incidence of seizure and cerebral infarction in pediatric patients with epileptic type MMD, in order to estimate the effect of the surgery treatment on these patients.

\section{Methods}

\section{Literature search}

We computerized searched the PubMed, Web of Science, Embase, Wanfang, and CNKI databases. A combination of keywords and similar strategies was used to identify previously published studies. The medical subject heading $(\mathrm{MeSH})$ key words were moyamoya disease, epilepsy or seizure, and surgery or operation. Two independent researchers (Liu J, Xu X) conducted separate literature searches. The last update for research was done in August 2019. No limitation on language was considered. After the removal of duplicate articles, a total of 523 articles were found (Fig. 1).

\section{Criteria for inclusion and exclusion}

Articles were included in the meta-analysis if they met the following criteria: (1) prospective and retrospective cohort studies on patients with epileptic type MMD, (2) enrolled patients are younger than 18 years old, (3) at least 5 epileptic type MMD patients were included in the study, (4) chose direct and indirect revascularizations or the combination surgery treatment for these patients, (5) the prognosis of these patients after surgery was described in detail, including the postoperative incidence of seizure and cerebral infarction. We excluded all of the reviews, case reports, articles without full text, or not be translated into English or Chinese. We also excluded the studies without detail about epileptic type MMD, surgical treatment, or outcome analysis after surgery. No randomized controlled trials were found. Finally, seven cohorts $[2,6,15-19]$ were considered eligible for the postoperative incidence of seizure and cerebral infarction in pediatric patients with epileptic type MMD (Fig. 1).

The following data were extracted from each study: (1) age range of the patients, (2) follow-up period, (3) other preoperative clinical manifestations except epilepsy, (4) interval between onset of clinical symptoms and surgery, (5) the modality of revascularization surgery (direct, indirect, combined), (6) angiographic and perfusion characteristics (Suzuki stage [20]), (7) postoperative complications (other than seizures and ischemic events), (8) the number of epileptic type cases, (9) the number of postoperative seizure cases, and (11) the number of postoperative cerebral infarction cases.

\section{Statistical analysis}

Meta-analyses of a single rate were carried out by using RStudio version 3.6.1 (2019-07-05). The $I^{2}$ statistic was used to quantify heterogeneity $\left(I^{2}<25 \%\right.$, low heterogeneity). The fixed-effects models were used to calculate an overall pooled proportion and $95 \% \mathrm{CI}$ when the results presented as low heterogeneity. Linear regression test of funnel plot asymmetry was used to estimate the potential publication bias $(P>0.05$, no publication bias). Influential analysis was used to detect whether there were some studies exert a very high influence on our overall results.

\section{Results}

All of the details of the included studies are listed in Table 1.

The summarized pooled postoperative incidence rate of seizure in pediatric patients with epileptic type MMD in the seven studies using the fixed-effects models was $23.44 \%$ (95\% CI 14.39-33.63\%) with low heterogeneity $\left(\mathrm{Tau}^{2}=0, I^{2}=0 \%\right.$ (95\%CI 0-67.2\%), $P=0.5$ ) (Fig. 2 a). Low publication bias was estimated by the linear regression test of funnel plot asymmetry $(P=0.33)$ (Fig. 3a).

The summarized pooled postoperative incidence rate of seizure in pediatric patients with epileptic type MMD would change $\leq 2.6 \%$ after the exclusion of any studies. The maximum increase of the rate would be $2.6 \%$ after the exclusion of the study by Nakase H, et al. (1993) [6], whereas the maximum reduction would be $1.9 \%$ after the exclusion of the study by Ulrich PT, et al. (2011) [16]. Removing any of the findings of these studies will not make the heterogeneity of the studies significant $\left(I^{2}\right.$ $=0 \%$ ).

The summarized pooled postoperative incidence rate of cerebral infarction in pediatric patients with epileptic type MMD in the four studies using the fixed-effects models was $9.12 \%$ (95\% CI $0.75-22.34 \%)$ with low heterogeneity $\left(\mathrm{Tau}^{2}=0, I^{2}=0 \%\right.$ (95\% CI $\left.0-82.5 \%\right), P=$ 0.45) (Fig. 2 b). Low publication bias was estimated by the linear regression test of funnel plot asymmetry $(P=$ 0.70) (Fig. 3b).

The summarized pooled postoperative incidence rate of cerebral infarction in pediatric patients with epileptic type MMD would change $\leq 3.2 \%$ after the exclusion of any studies. The maximum increase of the rate would be $2.4 \%$ after the exclusion of the study by Sainte-Rose C, et al. (2006) [15] or Caldarelli M, et al. (2001) [17], whereas the maximum reduction would be $3.2 \%$ after the exclusion of the study by Choi JI, et al. (2015) [2]. Removing any of the findings of these studies will not 
Table 1 The details of the included studies

\begin{tabular}{|c|c|c|c|c|c|c|}
\hline$n$ & $\begin{array}{l}\text { Included } \\
\text { studies }\end{array}$ & Age range (years) & $\begin{array}{l}\text { Follow-up } \\
\text { period(years) }\end{array}$ & $\begin{array}{l}\text { Preoperative clinical } \\
\text { manifestations (except } \\
\text { seizure) }\end{array}$ & $\begin{array}{l}\text { Interval between onset } \\
\text { of clinical symptoms and } \\
\text { surgery }\end{array}$ & Surgery modality \\
\hline 1 & $\begin{array}{l}\text { Sainte-Rose } \\
\text { C, et al. } \\
\text { (2006) [15] }\end{array}$ & $3.5-16$ & $2.1-5.6$ & $\begin{array}{l}\text { Cerebral ischemia, } \\
\text { headache }\end{array}$ & Unknown & $\begin{array}{l}\text { Indirect (multiple bur } \\
\text { hole) }\end{array}$ \\
\hline 2 & $\begin{array}{l}\text { Choi Jl, et al. } \\
\text { (2015) [2] }\end{array}$ & $2-15$ & $2-12$ & Cerebral ischemia & An average of 7.4 months & Indirect (EDAS) \\
\hline 3 & $\begin{array}{l}\text { Nakase } H_{1} \\
\text { et al. (1993) } \\
{[6]}\end{array}$ & $0.4-12$ & $0.5-17.3$ & No description & $\begin{array}{l}\text { Within } 1 \text { year to more than } \\
3 \text { years }\end{array}$ & $\begin{array}{l}\text { Combined (STA-MCA + } \\
\text { EMS) }\end{array}$ \\
\hline 4 & $\begin{array}{l}\text { Ulrich PT, } \\
\text { et al. (2011) } \\
{[16]}\end{array}$ & $1-18$ & $2-25$ & $\begin{array}{l}\text { Ischemic stroke, mental } \\
\text { retardation, headache }\end{array}$ & Unknown & $\begin{array}{l}\text { Indirect, direct, or } \\
\text { combined (EDAS, EMS, } \\
\text { STA-MCA + EMS) }\end{array}$ \\
\hline 5 & $\begin{array}{l}\text { Caldarelli M, } \\
\text { et al. (2001) } \\
{[17]}\end{array}$ & $0.6-9$ & $1.2-19$ & $\begin{array}{l}\text { Hemiparesis, } \\
\text { psychomotor retardation, } \\
\text { malformation, fever }\end{array}$ & 2-20 months & Indirect (EMS) \\
\hline 6 & $\begin{array}{l}\text { Ma Y, et al. } \\
\text { (2018) [18] }\end{array}$ & $2-18$ & $0.5-7.5$ & $\begin{array}{l}\text { Cerebral ischemia or } \\
\text { hemorrhage, perfusion } \\
\text { impairment }\end{array}$ & $0.7-113$ months & $\begin{array}{l}\text { Indirect, direct, or } \\
\text { combined (EDAS, bypass, } \\
\text { burr holes) }\end{array}$ \\
\hline 7 & $\begin{array}{l}\text { Yang H, et al. } \\
\text { (2019) [19] }\end{array}$ & $3.5-16$ & $0.2-1.2$ & No description & Unknown & combined \\
\hline$n$ & $\begin{array}{l}\text { Included } \\
\text { studies }\end{array}$ & angiographic characteristics & $\begin{array}{l}\text { Postoperative } \\
\text { complications }\end{array}$ & Epileptic type MMD cases & Postoperative seizure cases & $\begin{array}{l}\text { Postoperative ischemic } \\
\text { event cases }\end{array}$ \\
\hline 1 & $\begin{array}{l}\text { Sainte-Rose } \\
\text { C, et al. } \\
(2006)[15]\end{array}$ & Suzuki stage 2-4 & $\begin{array}{l}\text { Subcutaneous } \\
\text { effusions ( } 1 \\
\text { case) }\end{array}$ & 5 & 2 & 0 \\
\hline 2 & $\begin{array}{l}\text { Choi Jl, et al. } \\
\text { (2015) [2] }\end{array}$ & Suzuki stage 2-3 & No description & 7 & 1 & 2 \\
\hline 3 & $\begin{array}{l}\text { Nakase } H_{,} \\
\text {et al. (1993) } \\
{[6]}\end{array}$ & Suzuki stage 1-6 & No description & 23 & 4 & 3 \\
\hline 4 & $\begin{array}{l}\text { Ulrich PT, } \\
\text { et al. (2011) } \\
{[16]}\end{array}$ & Suzuki stage 2-3 & No description & 15 & 5 & Unknown \\
\hline 5 & $\begin{array}{l}\text { Caldarelli M, } \\
\text { et al. (2001) } \\
{[17]}\end{array}$ & $\begin{array}{l}\text { Stenosis or occlusion of } \\
\text { monolateral or bilateral ICA, } \\
\text { MCA, or ACA }\end{array}$ & $\begin{array}{l}\text { Epidural } \\
\text { bleeding (1 } \\
\text { case) }\end{array}$ & 5 & 3 & 0 \\
\hline 6 & $\begin{array}{l}\text { Ma Y, et al. } \\
(2018)[18]\end{array}$ & Suzuki stage: 1-5 & No description & 28 & 7 & Unknown \\
\hline 7 & $\begin{array}{l}\text { Yang H, et al. } \\
(2019)[19]\end{array}$ & Unknown & No description & 9 & 1 & Unknown \\
\hline
\end{tabular}

Abbreviations: EDAS encephaloduroarteriosynangiosis, EMS encephalomyosynangiosis, STA-MCA superficial temporal artery-middle cerebral artery, ICA internal carotid artery, MCA middle cerebral artery, ACA anterior cerebral artery, TIA transient ischemic attack

Suzuki stage [20]: stage 1 no abnormal findings can be observed except for carotid fork stenosis; stage 2 the stenosis has progressed at the carotid fork; the moyamoya vessels can be observed and all the main cerebral arteries are dilated; stage 3 the moyamoya vessels develop on the base of the brain and its constituent vessels are comparatively thick and rough with the anterior or middle cerebral arteries missing; stage 4 the moyamoya vessels become thin with the anterior and middle cerebral arteries missing; stage 5 the moyamoya vessels contract to the base of the brain and even the posterior cerebral arteries disappear; stage 6 the intracranial internal carotid artery is not visualized; the intracerebral vessels are perfused with blood from the external carotid artery and/or vertebral artery.

make the heterogeneity of the studies significant $\left(I^{2}=\right.$ $0 \%)$.

\section{Discussion}

The management of MMD includes medical treatment and surgical treatment. Platelet aggregation inhibitors [21]or calcium channel blockers [21, 22] may generate excellent but transient effects, could be only applied to mild cases [17] or acute phase of stroke [11]. Surgical treatment is considered to be the most effective method to treat MMD, especially for MMD, manifesting as a cerebral ischemic symptom [11]. However, few studies focus on the surgical treatment of epileptic type MMD, and there is a lack of randomized controlled studies and 

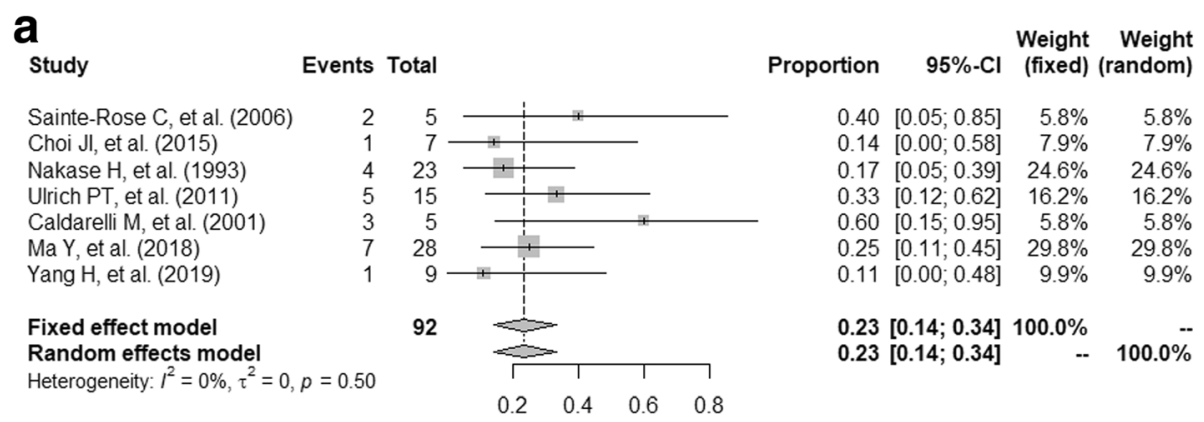

b

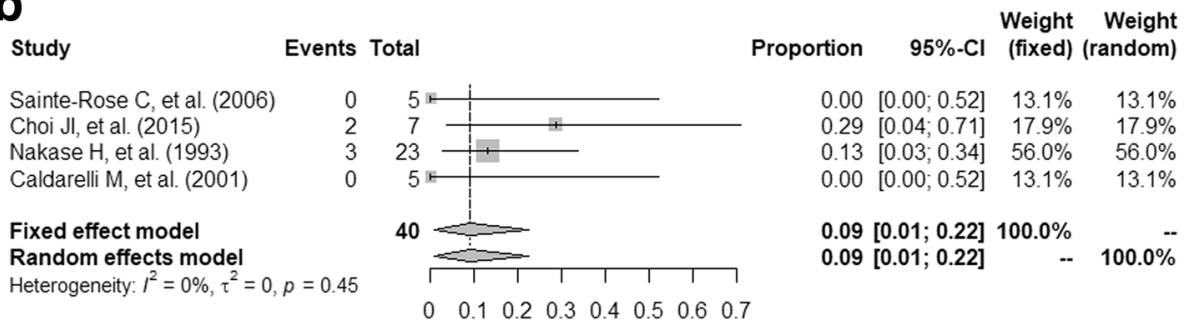

Fig. 2 forest plot of postoperative incidence. a Forest plot of postoperative incidence of seizure in patients with epileptic type MMD. b Forest plot of postoperative incidence of cerebral infarction in patients with epileptic type MMD

meta-analysis. Thus, we reviewed the current literature and summarized the efficacy of surgical treatment for epileptic type MMD.

We calculated an overall pooled postoperative incidence of seizure in pediatric patients with epileptic type MMD, which was $23.44 \%$. Most of the patients with epileptic type MMD suffered seizures after surgery could be controlled by anti-epileptic drugs [15-17], and only very few patients deteriorated or without improvement after surgery $[2,18]$. We also calculated the overall pooled postoperative incidence of cerebral infarction in pediatric patients with epileptic type MMD, which was $9.12 \%$. The data suggest that surgical revascularization is a secure intervention for pediatric epileptic type MMD and most treated patients could gain symptom improvement [23].

The risk factors for epilepsy and ischemic event after cerebral revascularization in pediatric patients with epileptic type MMD were various. Age of patients, course of clinical symptoms, and severity of clinical presentations may all affect the prognosis of operation $[6,18$, 19]. Only one study [18] explored the risk factor of seizure recurrence in epileptic type MMD. They identified the duration of epilepsy as an independent risk factor for recurrent seizure after surgery in pediatric patients with epileptic type MMD. Nevertheless, the intervals between onset of clinical symptoms and surgery in our study were not consistent; it is particularly important to group analysis by different course in the future. In addition, age less than 1 year and severe abnormal imageological findings correlate with poor prognosis of epileptic type
MMD [3], infantile onset and severe clinical manifestations are more likely to have recurrent seizures or cerebral infarction after surgery. In our study, although the age range and angiographic characteristics were not consistent among the included studies, the pooled rates still showed low heterogeneity. Hence, group analysis should be considered according to different ages and severity of clinical presentations in the future.

Most scholars believed that seizure could be associated with ischemia [19]. Among the studies included in our meta-analysis, it is hard to identify whether the preoperative seizures came from ischemia events, due to epilepsy and ischemic event always exist together and has an analogical progression in most of the patients with MMD [6]. Choi et al. [2] reported that surgery could prevent epileptic seizures and obtained more approving clinical outcomes when applied to patients with epileptic type MMD compared to ischemic type MMD, but there were no differences in postoperative neuroimaging and hemodynamic changes between the two groups. Yang et al. [19] did not consider the presence of epileptic symptoms before surgery is a risk factor for postoperative epileptic recurrence. The different outcomes between epileptic type and ischemic type need more future studies.

Different operation procedures (indirect, direct, or combined) may affect the prognosis of MMD. Indirect revascularization is widely used in pediatric patients because of its simple procedure and few complications [24-26]. Many studies confirmed the effectiveness of this modality, but direct revascularization can improve 


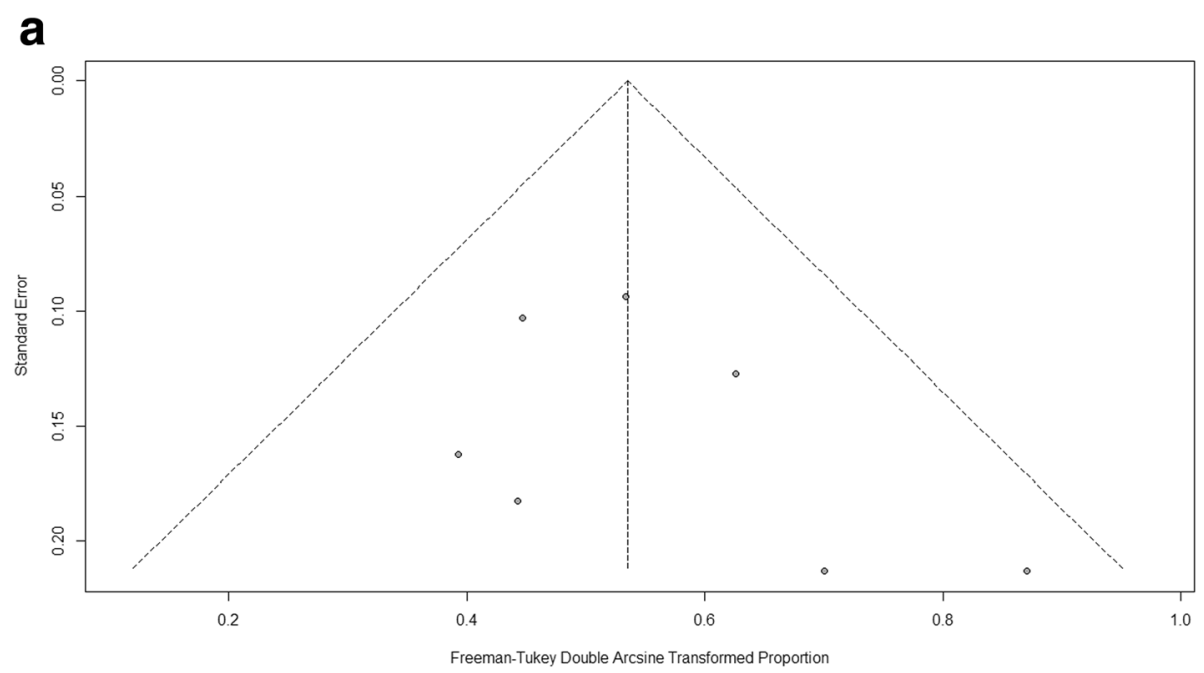

b

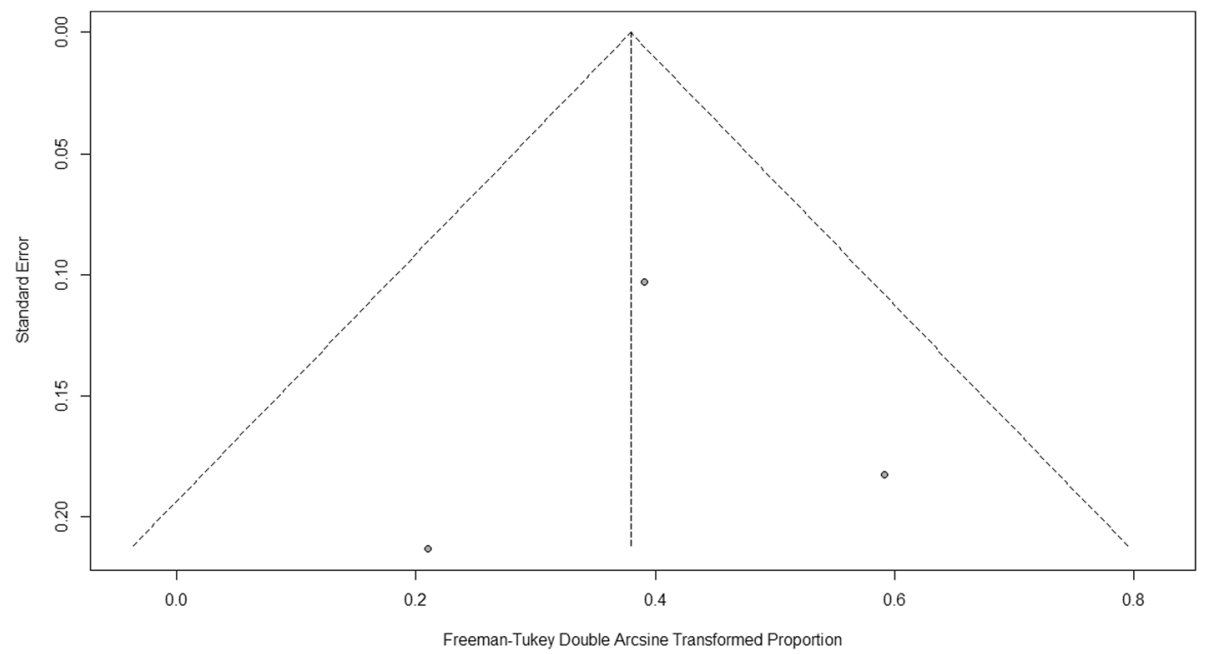

Fig. 3 Funnel plot of postoperative incidence. a Funnel plot of postoperative incidence of seizure in patients with epileptic type MMD. b Funnel plot of postoperative incidence of cerebral infarction in patients with epileptic type MMD

cerebral blood flow perfusion immediately as its advantage $[25,26]$. Therefore, more and more surgeons chose combined revascularization to treat patients with MMD $[27,28]$, just as most of the included studies $[6,16,18$, $19]$ in our meta-analysis. However, in our analysis, different modalities did not show obvious different postoperative incidences of seizure and cerebral infarction, which was in line with the finding of $\mathrm{Ma} \mathrm{Y}$ et al. [18], who believed that the surgical modalities would not affect the outcome of the surgery. Further research on the effect of the different operation techniques is needed.

There are many possible causes of postoperative seizure in MMD patients: ischemic events, intracranial hemorrhage, hyperperfusion syndrome, poor scalp healing and infection, surgical procedure [29]. Seldom studies could identify where the postoperative seizure came from. No postoperative hyperperfusion mentioned in the included studies. Only two included studies described the postoperative complications of patients with epileptic type MMD. In the study by Sainte-Rose C, et al. [15], one patient suffered subcutaneous cerebrospinal fluid effusions and had a single seizure 5 months postoperatively. Due to such a long interval and no infection occurred, this seizure was unlikely caused by subcut effusion. In the study by Caldarelli $\mathrm{M}$, et al. [17], one patient experienced epidural bleeding during the surgery, and died 6 months later. This patient presented seizure postoperation, but controlled by medication well. It is hard to say whether the seizure was induced by this postoperative complication. But omitting this study will not change the pooling results in our analysis.

There were several limitations in our study: the numbers of patients and studies were all tiny, and all of these 
studies were retrospective and non-randomized. That may because the incidence of epileptic type MMD is relatively low, and few scholars focus on this type of MMD. Follow-up periods were not consistent among individuals, ranging from 0.2 to 25 years, which implies that the observational time of some patients may not be sufficient. Most of the studies did not describe the detail of the clinical feature of this type of patients, which results in the difficulty of distinguishing whether ischemic events or other reasons cause the patient's preoperative and postoperative seizures. In a word, future studies should focus on the epileptic type MMD in large-scale randomized controlled clinical studies.

\section{Conclusions}

Evidence from this study suggests that the postoperative incidence of seizure and cerebral infarction is relatively low. Surgery is an effective and secure therapy for pediatric patients with epileptic type moyamoya disease.

\section{Abbreviations}

MMD: Moyamoya disease; ICA: Internal carotid artery; MCA: Middle cerebral artery; ACA: Anterior cerebral artery; TIA: Transient ischemic attack; EDAS: Encephaloduroarteriosynangiosis; EMS: Encephalomyosynangiosis; STA-MCA: Superficial temporal artery-middle cerebral artery

\section{Acknowledgements}

Not applicable

\section{Authors' contributions}

$J$ computerized searched the PubMed, Web of Science, and Embase databases; identified eight cohort studies finally; conducted the statistical analysis; and was the major contributor in writing this manuscript. QX computerized searched the Wanfang and CNKI databases, and assisted $J$ to aggregate data for analysis. HN was responsible for proofreading the collected studies and rechecking the data. RW was responsible for ensuring that the final statistical analysis of the data was accurate and reliable. XY mainly designed the structure of this manuscript, and reviewed and modified it at last. XL reviewed and modified this manuscript, and was the major corresponding author of this manuscript. All authors read and approved the final manuscript.

\section{Funding}

Not applicable

\section{Availability of data and materials}

All data generated or analyzed during this study are included in these published articles.

\section{Ethics approval and consent to participate}

Not applicable

\section{Consent for publication}

Not applicable

\section{Competing interests}

The authors declare that they have no competing interests.

\section{Author details}

${ }^{1}$ Peking University International Hospital, Department of Neurology, Peking University, Beijing, China. 'Boston Children's Hospital, Division of Epilepsy and Clinical Neurophysiology, Department of Neurology, Harvard Medical School, Boston, USA. ${ }^{3}$ Peking University International Hospital, Department of Neurosurgery, Peking University, Beijing, China. ${ }^{4}$ Beijing Tiantan Hospital, Department of Neurosurgery, Capital Medical University, Beijing, China.
Received: 29 May 2020 Accepted: 14 December 2020

Published online: 02 February 2021

\section{References}

1. Zhang $H$, Zheng L, Feng L. Epidemiology, diagnosis and treatment of moyamoya disease. Exp Ther Med. 2019;17(3):1977-84.

2. Choi Jl, Ha SK, Lim DJ, et al. Differential clinical outcomes following encephalo-duroarteriosynangiosis in pediatric moyamoya disease presenting with epilepsy or ischemia. Childs Nerv Syst. 2015;31(5):713-20.

3. Suyama K, Yoshida K, Takahata H, et al. Pediatric Moyamoya disease presenting with intracerebral hemorrhage-report of three cases and review of the literature. Clin Neurol Neurosurg. 2008;110(3):270-5.

4. Suzuki J, Kodama N. Moyamoya disease-a review. Stroke. 1983;14(1):104-9.

5. Mikami T, Ochi S, Houkin K, et al. Predictive factors for epilepsy in moyamoya disease. J Stroke Cerebrovasc Dis. 2015;24(1):17-23.

6. Nakase $H$, Ohnishi $H$, Touho $H$, et al. Long-term follow-up study of "epileptic type" moyamoya disease in children. Neurol Med Chir (Tokyo). 1993;33(9): 621-4.

7. Matsushima Y, Aoyagi M. Discussion of disease typing moyamoya disease: Especially from the analysis of our so-called "epileptic type" moyamoya patient. Shoni No Noshinkei. 1990;15: 235-241. (in Japanese).

8. Jin SC, Oh CW, Kwon OK, et al. Epilepsy after bypass surgery in adult moyamoya disease. Neurosurgery. 2011;68(5):1227-32.

9. Yonekawa Y, Kahn N. Moyamoya disease. Adv Neurol. 2003;92:113-8.

10. Hoshino H, Izawa $Y$, Suzuki N, et al. Epidemiological features of moyamoya disease in Japan. Neurol Med Chir (Tokyo). 2012;52(5):295-8.

11. Research Committee on the Pathology and Treatment of Spontaneous Occlusion of the Circle of Willis. Guidelines for diagnosis and treatment of moyamoya disease (spontaneous occlusion of the circle of Willis). Neurol Med Chir (Tokyo). 2012;52(5):245-66.

12. Houkin K, Kuroda S, Nakayama N. Cerebral revascularization for moyamoya disease in children. NeurosurgClin N Am. 2001;12(3):575-584, ix.

13. Morimoto M, Iwama T, Hashimoto $\mathrm{N}$, et al. Efficacy of direct revascularization in adult Moyamoya disease: haemodynamic evaluation by positron emission tomography. Acta Neurochir (Wien). 1999;141(4):377-84

14. Scott RM, Smith $J$, Robertson $R L$, et al. Long-term outcome in children with moyamoya syndrome after cranial revascularization by pialsynangiosis. J Neurosurg. 2004;100(2 Suppl Pediatrics):142-9.

15. Sainte-Rose C, Oliveira R, Puget $\mathrm{S}$, et al. Multiple bur hole surgery for the treatment of moyamoya disease in children. J Neurosurg. 2006;105(6 Suppl): 437-43.

16. Ulrich PT, Januschek E. Revascularisation surgery and long-term follow-up in juvenile Moyamoya syndrome: a retrospective analysis. Acta Neurochir Suppl. 2011;112:39-43.

17. Caldarelli M, Di Rocco C, Gaglini P. Surgical treatment of moyamoya disease in pediatric age. J Neurosurg Sci. 2001;45(2):83-91.

18. Ma Y, Zhao M, Zhang Q, et al. Risk factors for epilepsy recurrence after revascularization in pediatric patients with moyamoya disease. J Stroke Cerebrovasc Dis. 2018;27(3):740-6.

19. Yang H, Su J, Ni W, et al. Risk factors for epilepsy after cerebral revascularization in patients with moyamoya disease. Chin J Neurosurg. 2019; 35(7):664-668. (in Chinese).

20. Suzuki J, Takaku A, Kodama N, et al. An attempt to treat cerebrovascular 'Moyamoya' disease in children. Childs Brain. 1975;1(4):193-206.

21. Battistella PA, Carollo C. Clinical and neuroradiological findings of moyamoya disease in Italy. Clin Neurol Neurosurg. 1997:99(Suppl 2):S54-7.

22. Hosain SA, Hughes JT, Forem SL, et al. Use of a calcium channel blocker (nicardipine $\mathrm{HCl}$ ) in the treatment of childhood moyamoya disease. J Child Neurol. 1994;9(4):378-80

23. Fung LW, Thompson D, Ganesan V. Revascularisation surgery for paediatric moyamoya: a review of the literature. Childs Nerv Syst. 2005;21(5):358-64.

24. Kim W, Lee EY, Park SE, et al. Neuropsychological impacts of indirect revascularization for pediatric moyamoya disease. Childs Nerv Syst. 2018; 34(6):1199-206.

25. Wang KC, Phi JH, Lee JY, et al. Indirect revascularization surgery for moyamoya disease in children and its special considerations. Korean J Pediatr. 2012:55(11):408-13.

26. Macyszyn L, Attiah M, Ma Ts. et al. Direct versus indirect revascularization procedures for moyamoya disease: a comparative effectiveness study. J Neurosurg. 2017;126(5):1523-29. 
27. Rashad S, Fujimura M, Niizuma K, et al. Long-term follow-up of pediatric moyamoya disease treated by combined direct-indirect revascularization surgery: single institute experience with surgical and perioperative management. Neurosurg Rev. 2016;39(4):615-23.

28. Kazumata $\mathrm{K}$, Ito $\mathrm{M}$, Tokairin $\mathrm{K}$, et al. The frequency of postoperative stroke in moyamoya disease following combined revascularization: a single-university series and systematic review. J Neurosurg. 2014;121(2):432-40.

29. Yu J, Shi L, Guo Y, et al. Progress on complications of direct bypass for moyamoya disease. Int J Med Sci. 2016;13(8):578-87.

Ready to submit your research? Choose BMC and benefit from:

- fast, convenient online submission

- thorough peer review by experienced researchers in your field

- rapid publication on acceptance

- support for research data, including large and complex data types

- gold Open Access which fosters wider collaboration and increased citations

- maximum visibility for your research: over $100 \mathrm{M}$ website views per year

At $B M C$, research is always in progress.

Learn more biomedcentral.com/submissions 